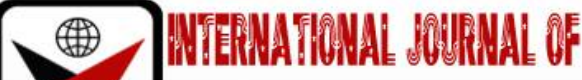

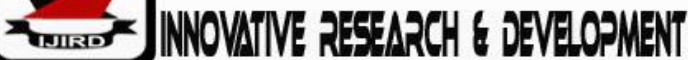

ISSN 2278 - 0211 (Online)

\section{Urbanization as a Driver of Flood Disaster Events: A Study Based on Sri Lankan Flood Events}

\author{
D. Chathumani \\ Temporary Instructor, Department of Computer Teaching Unit \\ University of Colombo, Sri Lanka
}

\begin{abstract}
:
The frequency of natural disasters has increased over time with the alteration of ecological systems due to increasing urban populations. Analysis was carried out to investigate this relationship between urban population growth and disaster impacts, based on Sri Lankan percentage urban population, flood disaster occurrence and flood impact, using SPSS and Excel. Results showed in increase in flood events and impacts with the increasing urbanization. Due easy and quality access to facilities, infrastructure and services, people are attracted towards cities. In general, the ecosystems and the earth are formed naturally in a way to maintain and balance the natural disaster phenomena and to reduce the impact. However, at present, as the naturally available space in the city areas to supply the needs is less than what is expected, people tend to alter the natural ecosystems to develop settlements, industries and cultivations creating and inducing the disaster prevalence and related impacts
\end{abstract}

Keywords: Population, urban, disasters, impact

\section{Introduction}

Disasters at present have become a common global burden with a remarkable percentage of loss (Goodfellow, 2012) and a critical issue in any country. The increasing incidents of natural disasters take a larger toll (Alcántara-Ayala, 2002), diminishing the quality of life in any country, especially in developing countries (Hoffman, 2003). The severity of any disaster depends on hazard, vulnerability and capacity, due to its link. A hazard is any substance, phenomenon or situation, which has the potential to cause disruption or damage to people, their property, their services and their environment (Asian Disaster Preparedness Center, 2011). Similarly vulnerability is, being prone to or susceptible to damage or injury (Blaikie et al., 1996). 'Disaster' is generally explained with an equation, Disaster $=$ Hazard + Vulnerability/ Capacity ('What is a disaster?-IFRC), which states that a disaster occurs when a hazard impact on vulnerable communities with an inability to cope up with the negative consequences of the hazard.

Floods are natural catastrophic disaster events that are caused by nature or any natural processes of the earth, with no direct contribution from human being (Skoufias, 2003). Today flood disasters are identified as a global issue and they are popular as the most damaging type of disasters on developing countries (Sohail and Ilyas, 2012). Natural disasters can be classified into five basic types (CRED, 2010) as follows. Geophysical: events originating from solid earth, Meteorological: events caused by short-lived/small to meso-scale atmospheric processes, Hydrological: events caused by deviations in the normal water cycle and/or overflow of bodies of water caused by wind set-up, Climatological: events caused by long-lived/meso- to macro-scale processes, Biological: disasters caused by the natural exposure of living organisms to germs and toxic substances (CRED, 2010). Floods fall under hydrological disasters. At present, floods occur in a dramatic frequency and this have led researchers to focus more towards flood disaster management. For this dramatic frequency, there are many possible reason such as, destruction of forests, wetlands, agricultural areas and fresh water bodies, which are the outcomes of over use of nature and environment by people (Ozmen, 2006). This type of mal use of nature and environment is a result of many contributing factors, specially a result of modern urbanization (Tyagi, 2014) which is a common phenomenon in, both developed and developing countries. This modern urbanization has led to the alterations of natural settings, increasing the disaster risk and the vulnerability.

Urbanization is the demographic process by which an increasing share of the national population lives within urban settlements. When the majority of the livelihoods of the settlers derive from farming occupations to non-farm occupations the settlements in urban area increase (Tyagi, Garg and Paudel, 2014) the urban expansion increases. From the past few decades the degree and the level of urbanization has increased. Most importantly a rapid urbanization would arise in developing countries than in developed countries (United Nations, Department of Economic and Social Affairs, 2014). In general urbanization is referred to the change in size, density, and heterogeneity of cities. This kind of rural population migration to cities seeking for employment, education and other livelihood opportunities result in majority of the world's population to reside in urban areas (Stage, 2016). In 2014, most of the world's population (54\%) resided in urban areas and it is predicted that, by $2050,66 \%$ percentage of the world population will be living in urban areas. 
Modern urbanization positively and negatively correlates with social, economic and environmental factors causing both good and bad impacts on the social, economic and environmental settings. Urbanization positively correlate with expanding education systems, entrepreneurs and entrepreneurship, accumulation of people and firms (Arouri et al., 2014) whereas negatively correlate with, land security, water quality, air quality and waste disposal (Uttara, 2012). When consider the disaster events and impact, a positive correlation is shown, depicting the increase of disaster events and impacts along with increasing urban population (Pelling, 2007), as urbanization increases the vulnerability and the risk of vulnerable communities. Even though it is quite clear that a high levels of disaster risk is associated with urbanization, the national and international attention and consideration on urbanization and disaster risk, vulnerability and impact is less and less studied. So, the study was carried out to examine the urbanization in relation to disaster expects.

\section{Methodology}

This research was done adopting the steps, collection and development of the data base, data analysis and processing, data visualization and processing. Data was collected in secondary data collection. Data related to urbanization was collected from United Nations Population Division (World Urbanization Prospects:2018 update) and data related to disaster impacts was collected from disinventra disaster profile for past forty years. urban population growth of Sri Lanka over hundred years were crossed analyzed with different impact variables. The considered variables were, the number of exposed communities, disaster mortality, and compensation of infrastructure (Destroyed and damaged houses) and loss of livelihood (crops and cattle). Data analysis was done using Excel and spss statistics. Spearman correlation test was conducted for urban population growth and each impact variables. Excel 2013 was used to draw graphs to visualize the relationship between two considered variables.

\section{Results}

The section represents the results of the analysis. Figure 1 depicts the urban population growth of Sri Lanka, where figure 2-5 are the impact generated from considered variables.

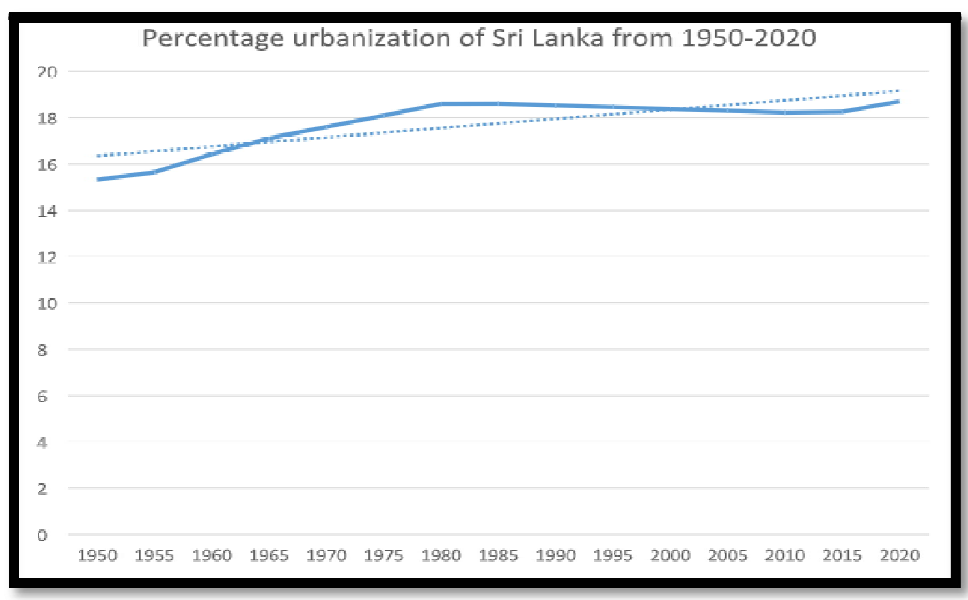

Figure 1: Urbanization Growth of Sri Lanka Over Hundred Years

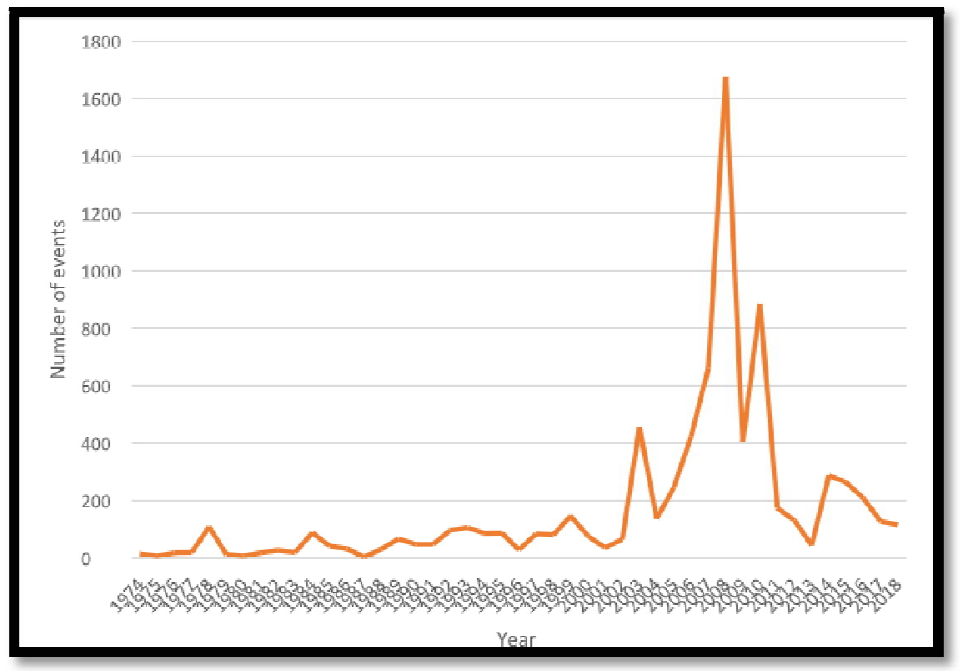

Figure 2: Number of Flood Disaster Events 


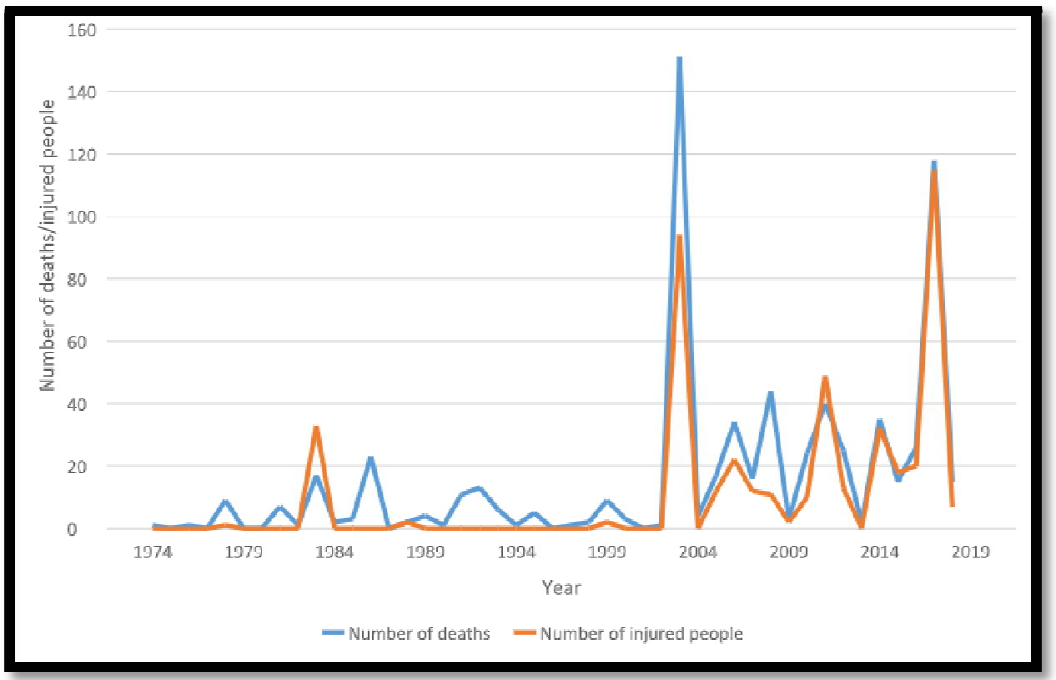

Figure 3: Number of Deaths and Injured People

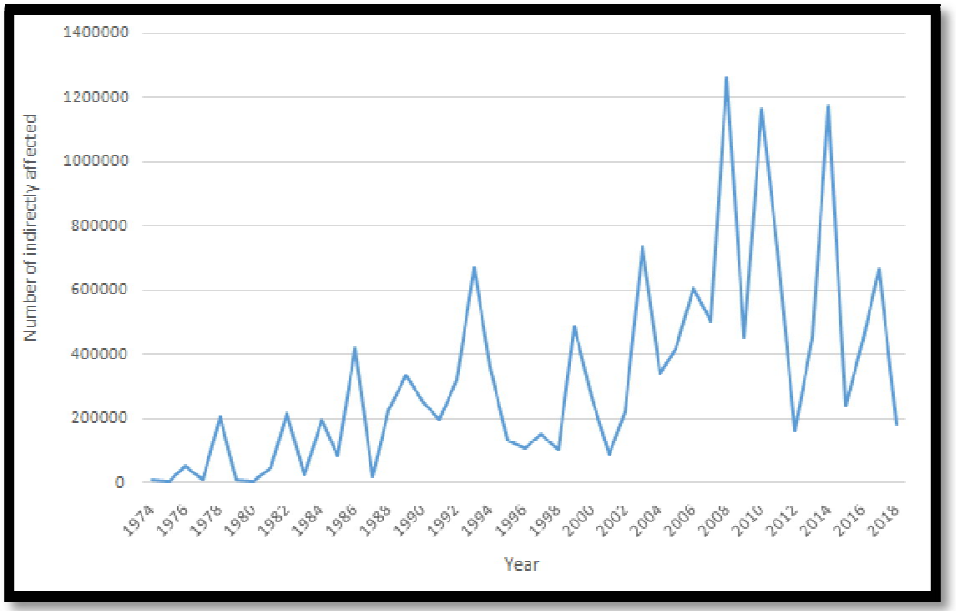

Figure 4: Number of Indirectly Affected People

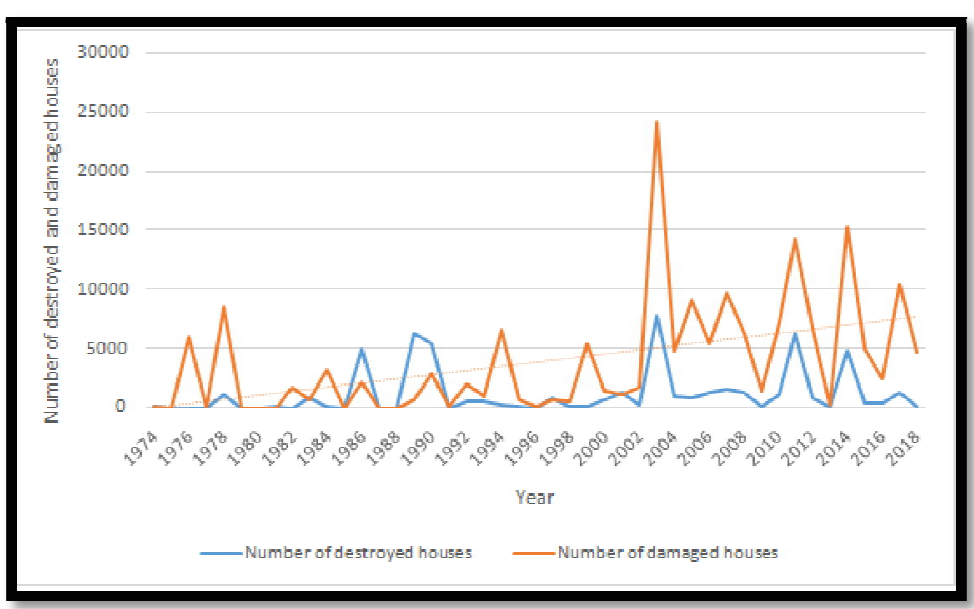

Figure 5: Number of Destroyed and Damaged Houses

As described by the figure 1, the country shows an increasing urban population over the considered years. In line with it, the number of disaster events and considered impact variables show an increase. As per figure 3, the number of deaths has increased with the increasing urban populations. As per figure 4 and figure 5, most of the destroyed houses and damaged houses have been recorded with high urban population growth.

To examine if the urban population and extend of impact correlate, spearman's correlation tests was conducted considering the selected variables and Results are as follows.

Number of deaths and urbanization growth positively correlated with a 0.05 Spearman correlation coefficient and with a 0.721 sig value. The number of destroyed houses positively correlated with urbanization growth and the correlation was depicted by a coefficient of 0.032 and a 0.813 sig value. A correlation coefficient of .0170 with a 0.233 sig value resulted for the test between urbanization growth and number of damaged houses. All the observed coefficient values were quite small while the resulted sig value was comparatively high. The correlation between the number of exposed 
people and the urbanization growth depicted the same pattern followed by the other variables. As the correlation values are much smaller and the sig values are larger it can be predicted of a very small positive relationship between, number of deaths, destroyed houses, damaged houses, exposed people and a negative with crop damage and cattle lost.

Finally, the correlation test was carried out for the total impact value in US\$ which resulted in a strong positive correlation coefficient of a 0.489 predicting that the total loss due to both natural and man-made disasters increase with the urbanization growth. The observed sig value of 0.096 .

\section{Discussion}

The indicated positive correlation between urbanization and disaster impacts through graphs could be identified and discussed in several aspects.

In general, the population growth in urban settlements brings huge challenges, as it transforms the terrain and fragments the natural landscape, reducing both biodiversity and the capacity of ecosystems to naturally mitigate and manage human activities (United Nations, Department of Economic and Social Affairs, 2014). At present the growth of cities is rapid and the expansion is highly disorganized. Especially the natural capacity to deliver basic services and infrastructure to a growing population is limited compared to the needs of growth. The biggest issue developing countries face about, urban population growth is the urban poor and migrants forming predominant populations of urban shanties and slums. These countries lack practical involvements to reverse the growth and expansion of poor migrant shanties and slums (Stage, 2016). The most important questioned to be discussed is how the urbanization can influence the disaster impact.

In nature most of the disasters causes loss of life, property and infrastructure damage, leaving a huge economic cost in in several minutes. The extent of impacts depends on several factors including the degree of the event, the extent of preparedness, population's resilience, available support, social capacity and several other factors. Any event will not be identified as a 'disaster' if it does not hit a vulnerable population (Disaster Preparedness Center, 2009).

Vulnerability and risk of natural disasters are influenced by this modern urbanization trends in several ways. These ways include, extensive environmental degradation, increase concentration of people (Pelling, 2007) and complex physical, socio-cultural, economic, and institutional interactions, which are triggered by, expansion of slums, deforestation, blocking of natural derange, soil erosion, and rising sea levels.

Environmental degradation is a key role which increases disaster vulnerability by reducing the environmental capacity to meet social and ecological needs. The capacity is reduced mainly due to the declining of ecosystems and ecosystem services (Asian Disaster Prepardness Center, 2004). These ecological changes highly influence on the frequency and the intensity of disasters (Zimmermann, 2015). As an example, urbanization in hilly areas increase the vulnerability to landslide disasters by removing vegetation cover and strengthening the soil erosion.

As this modern urbanization strength the accumulation of a large number of people to smaller areas, unplanned nature of the built environment reaches higher degrees (Prapathi 2017). Lack of adequate infrastructure and services, poor health services, unsafe housing poor solid waste management are the main characteristics of unplanned nature together with poverty contribute towards increasing the disaster vulnerability resulting in huge impacts (Sanderson, 2000). For instance, poor housing and poor building structures block the natural drainage systems and rain water infiltration to the ground, resulting in huge flash floods.

The complex physical, socio-cultural, economic, and institutional interactions largely contribute to man-made disasters. Especially to crimes wars and to road accidents. Unhealthy human relationships lead to human conflicts and this would result in unexpected disaster events. So, urbanization which leads to the accumulation of many people in different ethnic groups, religions and casts could increase vulnerability of conflicts leading to huge manmade disaster events.

While the above mention factors all increase risk, the same time, they decrease the resilience as a result of reduced wisdom of community, lack of preparedness, insufficient governance, and the unsustainable use of resources (Pelling, 2007). So the relationship observed through graphs can be clarified with respect to the above mentioned factors.

But the spearman's coefficient values resulted in both positive and negative correlations. Also the observed correlation values were small and the sig values were much large. As per the collected data, some counties were out layers compared to the rest of the countries due to very high impact records. Several such countries are Indonesia, Iran, Turkey and Sri Lanka and they may have directed to high sig values. As crops and cattle raring are rare in urbanized areas it could have resulted in a negative correlation value.

\section{Conclusion}

Urbanization, one of the huge challenges the world is facing not appropriately addressed, discussed and researched in relation to disasters, thus plays a vital role in managing mitigating and preparing for disasters. As the research demonstrated, without a doubt urbanization shows a positive relationship between, number of deaths, destroyed houses, damaged houses, exposed people and a negative with crop damage and cattle lost which are the impacts of disasters as urbanization due to its results such as environmental degradation, population concentration, increase poverty, unplanned nature of infrastructure and building and complex human relationships, highly contribute to increase the vulnerability and the risk to both natural and man-made disasters. Therefore the discussion of urbanization in the disaster management aspects should be incorporated in the development of national and international disaster management policies. 


\section{References}

i. Alcántara-Ayala, I. (2002) 'Geomorphology, natural hazards, vulnerability and prevention of natural disasters in developing countries', Geomorphology, 47(2-4), pp. 107-124. doi: 10.1016/S0169-555X(02)00083-1.

ii. Arouri, M. E. H. et al. (2014) 'Effects of urbanization on economic growth and human capital formation in Africa To cite this version ':, (119), pp. 1-22.

iii. Blaikie, P. et al. (1996) 'At Risk: Natural Hazards, People’s Vulnerability, and Disasters', Human Ecology, 24(1), pp. 141-145. doi: 10.4324/9780203428764.

iv. 'Combating Urban Hazard : A Qualitative Study of Disaster Preparedness in Dhaka, Bangladesh' (2017).

v. Disaster, A. (2004) 'Environmental Degradation and Disaster Risk Asian Disaster Preparedness Center', (February).

vi. Disaster Management Center (2009) 'Sri Lanka National Report on Disaster Risk, Poverty and Human Development Relationship', Human Development, (March).

vii. Goodfellow, M. J. (2012) Resilience to Natural Hazards in Developing Nations, POSTnote. Available at: http://www.parliament.uk/business/publications/research/briefing-papers/POST-PN402\%5Cnpapers2://publication/uuid/4D4D1677-0812-4292-9BAE-A9B262C5E2AC.

viii. Ozmen, F. (2006) 'The level of preparedness of the schools for disasters from the aspect of the school principals', Disaster Prevention and Management: An International Journal, 15(3), pp. 383-395. doi: 10.1108/09653560610669873.

ix. Pelling, M. (2007) 'Urbanization and disaster risk', In Panel Contribution to the Population- Environment Research Network Cyber Seminar on Population and Natural Hazards., (November).

X. Sanderson, D. (2000) 'Cities, disasters and livelihoods', (1998), pp. 93-102.

xi. Skoufias, E. (2003) 'Economic crises and natural disasters: Coping strategies and policy implications', World Development, 31(7), pp. 1087-1102. doi: 10.1016/S0305-750X(03)00069-X.

xii. Sohail, N. and Ilyas, S. (2012) The Impact of Natural Disasters on Economic Growth in Pakistan.

xiii. Stage, P. F. O. R. (2016) 'What Is the Impact of Urbanisation on Risk of , and Vulnerability To, Natural Disasters? What Are the Effective Approaches for Reducing Exposure of Urban Population To Disaster Risks ?', pp. 1-46.

xiv. The Centre for Research on the Epidemiology of Disasters (CRED) (2010) 'Technical References: DISASTER TYPES AND IMPACTS', Safer Homes, Stronger Communities: a Handbook for Reconstructing After Natural Disasters, pp. 339-45. doi: DOI: 10.1596/978-0-8213-8045-1.

xv. Tyagi, S., Garg, N. and Paudel, R. (2014) 'Environmental Degradation: Causes and Consequences', European Researcher, 81(8-2), p. 1491. doi: 10.13187/er.2014.81.1491.

xvi. United Nations, Department of Economic and Social Affairs, P. D. (2014) 'World Urbanization Prospects', United Nations, 12, p. 32. doi: 10.4054/DemRes.2005.12.9.

xvii. Uttara, S., Bhuvandas, N. and Aggarwal, V. (2012) 'Impacts of urbanisation on environment', IJREAS, 2.

xviii. What is a disaster? - IFRC (no date). Available at: http://www.ifrc.org/en/what-we-do/disastermanagement/about-disasters/what-is-a-disaster/ (Accessed: 27 October 2016).

xix. Zimmermann, K. F. (2015) 'Environmental Disasters and Migration', (9349). 